\title{
Daytime Wetting in Childhood
}

\author{
Wm. Lane M. Robson, M.D. ${ }^{1}$ \\ Alexander K.C. Leung, M.B. ${ }^{2}$ \\ David A. Bloom, M.D. ${ }^{3}$
}

\section{Introduction}

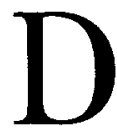
aytime wetting, a common problem in childhood, is defined as an unintended leakage of urine during waking hours in an individual old enough to maintain bladder control. Although usually self-limited and benign, occasionally the wetting is due to a more serious disorder. This article reviews the epidemiology, causes, evaluation, management, and prognosis of daytime wetting in children.

\section{Epidemiology}

Prevalence figures in the literature are difficult to interpret because definitions and study populations differ. In general, 3\%$4 \%$ of children between the ages of 4 and 12 years experience daytime wetting. The prevalence varies by age and sex. ${ }^{1,2}$ Bloom et $\mathrm{al}^{3}$ studied 1,192 individuals ranging in age from 1.5 to 27 years. Diurnal enuresis was present in $119(10 \%)$ patients, including $64 \%$ of those 2 years old or less, $29 \%$ of those 2 to $3,13 \%$ of those 3 to $4,7 \%$ of those 4 to 5 , and $10 \%$ of those 5 to 6 . The prevalence of diurnal enuresis by year in children from 6 to 18 years varied from 0 to $10 \%$. The prevalence in patients over 18 years of age was $2 \%$. Blomfield and Douglas $^{1}$ studied 5,386 6-year-old children in Edinburgh, Scotland, and found daytime wetting in $1.8 \%$ of males and $4.1 \%$ of females. In a study by Hellström et $\mathrm{al}^{4}$ of 3,556 7-year-old children in Sweden, daytime wetting was found in $6 \%$ of females and $3.8 \%$ of males.

Diurnal enuresis should be considered a problem in a child who is over the age of 4 years, in a child whose parents are concerned about the problem (regardless of the child's age), or in a child who was previously continent.

Approximately 50\%-60\% of children with daytime wetting also have nocturnal enuresis. 5 In contrast, only $8 \%$ of children with nocturnal enuresis have daytime wetting.

\section{Etiology}

The causes of daytime wetting in childhood are shown in Table 1.

The most common cause of daytime wetting in a preschool child is holding the urine to the last

1Department of Pediatric Nephrology, The Children's Hospital, Greenville Hospital System, Greenville, South Carolina, and Department of Pediatrics, University of South Carolina School of Medicine, Columbia; ${ }^{2}$ Department of Pediatrics, University of Calgary Faculty of Medicine and the Alberta Children's Hospital, Calgary, Canada; ${ }^{3}$ Department of Surgery, University of Michigan and Mott Children's Hospital, Ann Arbor, Michigan

Address correspondence to: Wm. Lane M. Robson, M.D., Director of Pediatric Nephrology, The Children's Hospital, Greenville Hospital System, 890 W. Faris Road, Suite 250, Box \#1, Greenville, SC 29605-4253

minute, or micturition deferral. Children commonly become absorbed in play activities and ignore the need to void. After several signals are ignored, a detrusor contraction occurs that the child cannot suppress, and an incontinent episode results.

Urinary tract infection (UTI) is a common cause of daytime wetting. ${ }^{6}$ Cystitis is associated with spontaneous detrusor contractions that lead to episodes of incontinence. When UTI is the only cause of daytime wetting, there is usually other evidence of infection, and the wetting resolves with appropriate antibiotic therapy. Urinary infection is more common in children with neurogenic bladder, urge syndrome, urethral obstruction, or ectopic ureter. In these situations, voiding dysfunction might be present in the absence of intercurrent episodes of UTI, and the symptoms do not completely resolve with antibiotic treatment.

Girls who use bubble bath might have daytime wetting secondary to chemical urethritis. ${ }^{5}$

Constipation may be associated with daytime wetting. Although the mechanism is not clear, it is possible that the pressure effect of stool in the descending or sigmoid colon triggers uninhibited contractions of the detrusor. ${ }^{7}$ Constipation is also associated with tonic contraction of the anal sphincter. Because the rectum and thie bladder are both innervated from sacral roots 2 to 4 , O'Regan et $\mathrm{al}^{7}$ suggested that constipation-induced 


\section{Table 1}

\section{CAUSES OF DAYTIME WETTING IN CHILDHOOD}

\author{
Micturition deferral \\ Urinary tract infection \\ Chemical urethritis \\ Constipation
}

Vaginal reflux of urine

Postvoid dribble syndrome

Daytime frequency syndrome

Giggle incontinence

Stress incontinence

Emotional stress

Neurogenic bladder

Urge syndrome

Urethral obstruction

Ectopic ureter

Diabetes mellitus

Diabetes insipidus

contraction of the anal sphincter might lead to uninhibited contractions of the detrusor.

Vaginal reflux of urine with voiding might occur in girls who do not open the labia with voiding. Some of the voided urine "refluxes" into the vagina. When the child stands to pull up the underwear and walk out of the bathroom, the urine in the vagina leaks out and wets the underwear. This is common in preschool children, who tend to fall into the toilet seat and compress the labia. ${ }^{8}$ The condition is more common in obese girls and in girls with anterior displacement of the posterior labial frenulum. ${ }^{9}$

The postvoid dribble syndrome is not well-documented in the medical literature, is commonly misdiagnosed as vaginal reflux of urine, and is more common than generally appreciated.$^{10}$ It typically presents in a 4 - to 6-year-old girl, who has a sensation of wetness immediately following voiding. The sensation may last up to $10 \mathrm{~min}$ utes. These girls wipe themselves repeatedly with toilet paper or change their panties because of the feeling of wetness. There is often no evidence of incontinent urine. This problem, of unknown etiology, is very frustrating for the child and the family. ${ }^{10}$

The daytime frequency syndrome commonly presents in 3- to 11-year-old males (mean age 5 years) who suddenly begin voiding as often as every 10 minutes..$^{11,12}$ Although frequency is the predominant symptom, daytime wetting has been reported in $25 \%$ of these children, typically in the younger ones who are unable to reach the bathroom in time. ${ }^{11}$ The etiology of this disorder is not known, although viral or chemical cystourethritis and anxiety have been suggested. ${ }^{11}$

Giggle incontinence is characterized by incontinence during laughter. ${ }^{13-16}$ Tickling or excitement may initiate the process. The problem may be familial, is more common in school-age girls, and tends to improve with increasing age. Glahn ${ }^{14}$ surveyed 99 student nurses in Denmark and found that eight (8\%) had experienced at least one episode of complete emptying of the bladder with laughter, nine $(9 \%)$ had experienced partial emptying and urgency, and seven (7\%) had experienced urgency alone. ${ }^{14}$ Giggle incontinence is a source of significant embarrassment to school-age children, who might choose not to attend social activities to avoid the problem.

Stress incontinence can occur in any situation associated with an increase in intra-abdominal pressure if the bladder outlet and proximal urethra fail to compensate for the abdominal pressure.

Emotional stress or excitement is another cause of daytime wetting, usually in children 2-6 years of age. The incontinence may present as an isolated episode associated with a specific stress, such as a sudden fright, or it may present as a persistent problem if the stress is prolonged.

Patients with a neurogenic bladder are likely to have daytime wetting. ${ }^{17} \mathrm{~A}$ neurogenic bladder can develop due to a lesion at any level in the nervous system, including the cerebral cortex, the spinal cord, or the peripheral nerves in the bladder. Reid and Brzyskowski ${ }^{18}$ reported that children with cerebral palsy have a high incidence of neurogenic bladder. Daytime wetting was present in $20(74 \%)$ of 27 patients with cerebral palsy. Patients with myelomeningocele almost always have daytime wetting. ${ }^{19}$ Other spinal cord abnormalities, such as caudal regression syndrome, tethered cord, and tumors, may be associated with daytime wetting. ${ }^{20}$

Urge syndrome is a common cause of persistent daytime wetting. A variety of other names have been suggested, including unstable bladder of childhood, irritable bladder, dysfunctional bladder, spastic bladder, detrusor-sphincter dyssynergia or dysfunction, occult neuropathic bladder, persistent infantile bladder, and subclinical neurogenic bladder. ${ }^{21-25}$ Children with urge syndrome often present with daytime wetting, bed-wetting, urinary frequency, urgency of micturition, and squatting behavior. Vesicoureteral reflux is common in these children, and UTI may be a complicating feature. ${ }^{24,25}$ Urodynamic studies often reveal unstable detrusor contractions early in the filling phase. ${ }^{21}$ In most children 
with urge syndrome, there is a period of normal voiding before the onset of symptoms, and the symptoms tend to resolve with time, becoming less common after age 10 to 12 years. ${ }^{23}$ Squatting behavior, a common and distinct symptom of urge syndrome, occurs when children try to suppress an unexpected or unwelcome detrusor contraction. Squatting is also referred to as the "curtsy sign," as originally described by Vincent. ${ }^{26}$ Squatting is a misnomer since a classic squat is a symmetrical posture, whereas children with urge syndrome typically sit asymmetrically on one heel. If a child is moved or lifted while squatting, incontinence is likely to follow. Squatting behavior is less common when patients are lying or sitting down. Vincent ${ }^{26}$ noted this and suggested the term "gravitational urgency." To avoid embarrassment, older children with squatting behavior sometimes pretend that something has dropped on the floor or that a shoelace has become untied. A child who is sitting might shift to the hard edge of the chair to suppress the need to void. The detrusor contraction may last several minutes.

Hinman syndrome may represent a severe variety of urge syndrome. ${ }^{25,27,28}$ Children with Hinman syndrome often have associated constipation and encopresis. Diagnostic imaging studies show a trabeculated bladder, significant postvoid residual urine, vesicoureteral reflux, dilation of the upper urinary tract, and renal scarring. ${ }^{21,27}$

Urethral obstruction may be associated with daytime wetting. The obstruction may be congenital, such as posterior urethral valves, congenital stricture, or urethral diverticuli, or it may be acquired, such as a traumatic or an infectious stricture. Traumatic strictures can develop after a traumatic urethral catheterization, foreign body in the urethra, or pelvic trauma. Infectious strictures are a complication of purulent urethritis due to such bacteria as Neisseria gonorrhoeae. Meatal stenosis is a common cause of distal urethral obstruction in circumcised males.

An ectopic ureter inserts in a location other than the lateral angle of the bladder trigone. Incontinence results when the insertion is distal to the external sphincter. Ectopic ureter is three to four times more common in females than in males. In females, the ectopic ureter might insert into the urethra, into an area adjacent to the external urethral meatus, or, less commonly, into the cervix, vagina, or uterus. The most common site is adjacent to the external urethral meatus. In males, an ectopic ureter usually inserts proximal to the external sphincter and incontinence does not result.
Patients with diabetes mellitus and diabetes insipidus have polyuria. Daytime wetting is more common in younger children with diabetes mellitus and diabetes insipidus, particularly when a bathroom is not nearby. Children with diabetes mellitus who were tested with uroflowmetry had a significantly increased voiding volume, increased average urinary flow, and increased delay until the first sensation of the need to void, compared with healthy children. ${ }^{99}$ These abnormal urodynamic features are consistent with damage to the afferent sensory pathways.

\section{Evaluation}

An algorithm illustrating the evaluation of a child with daytime

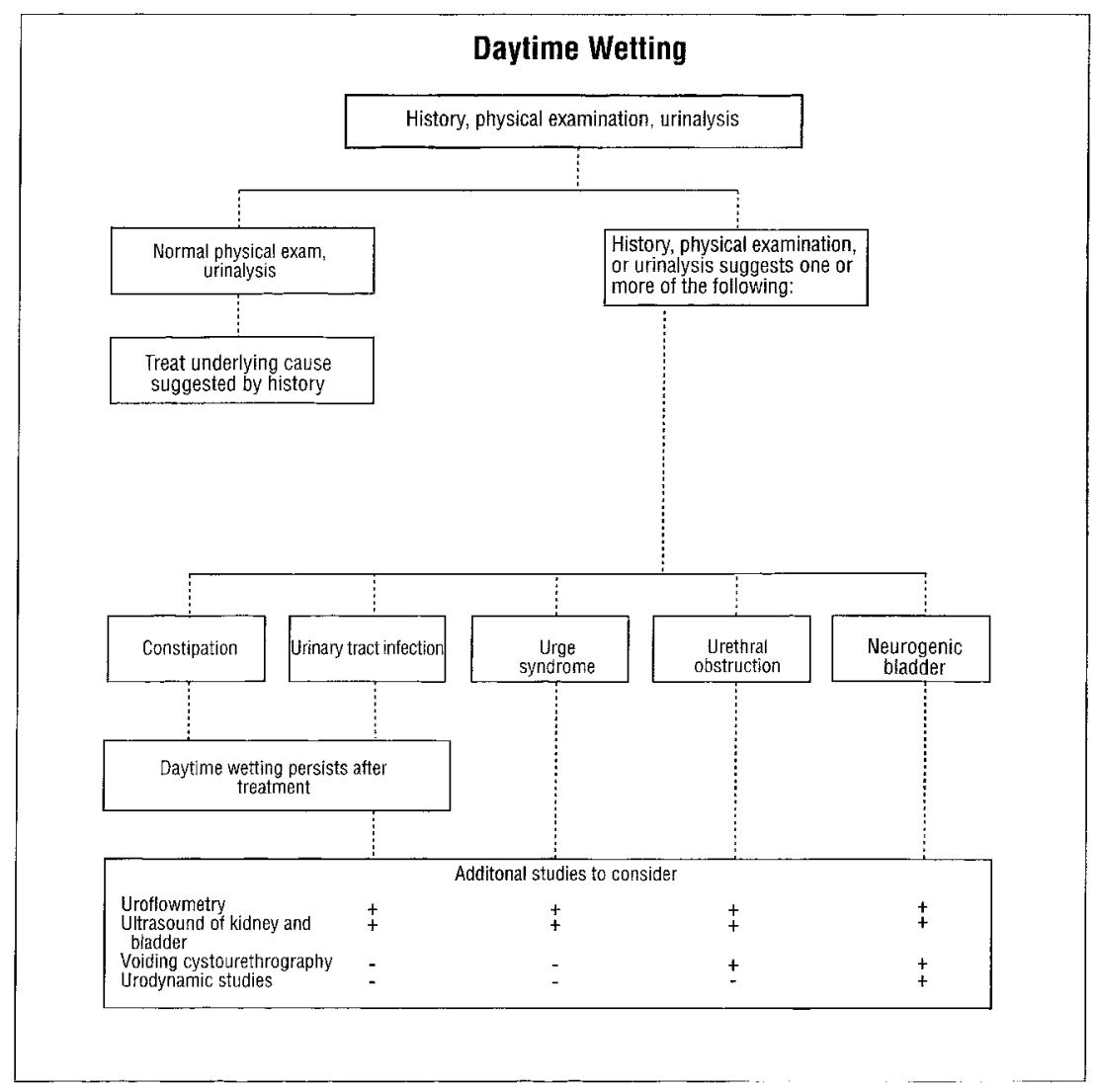

Figure 1. Algorithm for evaluation of patients with daytime wetting. 
wetting is shown in Figure 1.

\section{History}

The factors that should be considered in the evaluation of a child with daytime wetting include age and sex, whether the incontinence is a primary or a secondary problem, timing of incontinence in relation to voiding, frequency of wetting, circumstances immediately preceding an episode of incontinence, presence of associated bed-wetting, and presence of associated symptoms.

Age. Children who hold the urine to the last minute are usually 3-5 years of age. Most of these children were normally toilet trained and experienced a period of dryness before starting to wet. After toilet training is complete, a child's motivation to remain dry may decrease markedly. Recently toilettrained children are usually rewarded with smiles and hugs for going to the bathroom, and they enjoy the attention they receive from their caregivers. With time, toilet training becomes less an accomplishment and more an expectation, and the attention wanes. Children's environments provide endless diversions that keep them from responding to a full bladder. Daytime wetting due to micturition deferral is less common in schoolage children because wetting becomes a social problem and might result in embarrassment. Urinary tract infection might present with wetting at any age but, when associated with daytime wetting, is more common in the preschool toddler. Older children are able to plan their activities with proximity to a bathroom in mind. They are also likely to have better bladder control and are more able to suppress a spontaneous bladder contraction associated with cystitis. Daytime wetting due to constipa- tion and vaginal reflux of urine is more common in preschool children. The postvoid dribble syndrome is most common between the ages of 4 and 6 years. ${ }^{10}$ The daytime frequency syndrome is most common between the ages of 3 and 11 years. " Giggle incontinence and diabetes mellitus typically occur in school-age children. Patients with neurogenic bladder, spinal cord lesions, or stress incontinence may present with daytime wetting at any age. Patients with congenital problems, such as cerebral palsy or myelomeningocele, continue to wet past the age when toilet training would be expected. Patients with urge syndrome are usually $4-10$ years of age. Congenital urethral obstruction and ectopic ureter present with persistent wetting in toddlers at an age when they should otherwise be toilet trained.

Sex. Vaginal reflux of urine is limited by definition to females. Postvoid dribble syndrome, UTI, giggle incontinence, neurogenic bladder, urge syndrome, and ectopic ureter are more common in females. The daytime frequency syndrome is more common in males. The other causes of daytime wetting occur with equal frequency in males and females.

Primary or secondary problem. Primary diurnal enuresis may be defined as incontinence that persists beyond the age when a child would otherwise be expected to be toilet trained. Secondary diurnal enuresis may be defined as incontinence in a child who was successfully toilet trained and who has had at least 3 consecutive months of dry days. The causes of primary diurnal enuresis include congenital neurogenic bladder, such as cerebral palsy and myelomeningocele; congenital urethral obstruction; ectopic ureter; congenital diabetes insipidus; and any acquired cause that develops before the age that toilet training would be expected. The causes of secondary diurnal enuresis include micturition deferral, chemical urethritis, UTI, constipation, vaginal reflux of urine, postvoid dribble syndrome, daytime frequency syndrome, giggle incontinence, stress incontinence, emotional stress, neurogenic bladder, urge syndrome, traumatic or infectious urethral obstruction, diabetes mellitus, and acquired diabetes insipidus.

Timing of incontinence in relation to voiding. Children with vaginal reflux of urine and the postvoid dribble syndrome present with incontinence or the sensation of wet ness following voiding. Children with other causes of daytime wetting are incontinent before they are able to reach a toilet.

Frequency of wetting. Children with UTI, neurogenic bladder, urge syndrome, and urethral obstruction often wet more than five times per day in association with spontaneous contractions of the detrusor. Children with vaginal reflux of urine and the postvoid dribble syndrome have the sensation of wetness after each void. Children who hold the urine to the last minute usually wet only once or twice per day, but might wet more frequently depending on the availability of toilet facilities. Children with daytime frequency syndrome wet only once or twice a day, if at all, and at times when a bathroom is not convenient. Children with giggle and stress incontinence and children with incontinence related to emotional stress usually have isolated episodes of wetting, with periods of intervening dryness. Children with an ectopic ureter are always wet without any period of intervening dryness, although micturition occurs at normal intervals and without difficulty.

Circumstances immediately preced- 
ing wetting episodes. Children who hold their urine to the last minute are usually easy to identify. They often fidget, hold themselves in the genital area, press their legs together, squirm while sitting, or adopt other postures to suppress the need to void. Intense play activities, such as video games, are a common predisposing circumstance. Some elementary schoolage children prefer not to use the bathroom at school, or the school bus might be scheduled to leave before the child has time to use the toilet after school. If the trip home is long, the child will often wet before arriving or will have urgency on arrival at home. Giggle incontinence is associated with laughter. Stress incontinence develops with increases in intra-abdominal pressure, such as occur with coughing, straining, or physical activity, e.g., running, jumping, wrestling, and gymnastics. When emotional stress is the cause of incontinent episodes, there is often a history of a stressful event.

Associated bed-wetting. The causes of daytime wetting that are associated with bed-wetting include UTI, constipation, emotional stress, neurogenic bladder, urge syndrome, urethral obstruction, and ectopic ureter. If bed-wetting is present in a patient with one of the other causes of daytime wetting, a separate cause of the bed-wetting should be considered.

Associated symptoms. In children with UTI, there are usually associated symptoms of dysuria, frequency of micturition, urgency, and cloudy, foul-smelling urine. Children with constipation have hard, infrequent bowel movements. Children with a neurogenic bladder usually have symptoms related to the specific neurologic problem. Spinal cord lesions may be associated with encopresis or a gait disturbance. Children with urge syndrome present with urgency, frequency, and squatting behavior. Children with urethral obstruction usually have symptoms of a urinary stream abnormality, such as the need to push to initiate or sustain voiding and a weak, interrupted, or small-caliber urinary stream. A boy with urethral obstruction might compress his penis before voiding. ${ }^{30}$ It is helpful to review the symptoms and signs of a urinary stream abnormality with the parents, ask them to observe the stream at home, and to report their observations at the next office visit. Patients with diabetes mellitus or diabetes insipidus present with polydipsia and polyuria.

\section{Physical Examination}

A thorough physical examination is important for every child with daytime wetting. Although the examination is normal in most children, abnormal physical findings might be found in patients with UTI, constipation, stress incontinence, neurogenic bladder, urethral obstruction, or ectopic ureter. Patients with UTI may have fever, tenderness of the loin or suprapubic area, or genital inflammation or discharge. Constipation is suggested by the presence of hard stool in the left lower quadrant, and a rectal examination may reveal hard, impacted stool. Stress incontinence may be tested by observing the underwear after the patient jumps or coughs. To assess for neurogenic bladder, the neurologic examination should specifically assess the motor power, tone, spinal reflexes, sensation, and plantar reflexes in the lower extremities. The anal area should be tested for the anal wink. The lumbosacral spine area should be checked for abnormalities, including tufts of hair, dimples, masses, or abnormal skin coloration. In patients with urethral obstruction, the bladder and kidneys may be enlarged to palpation. It is important to observe the urinary stream in children who are suspected of having urethral obstruction. If the child uses the abdominal muscles to push or if the stream is weak, interrupted, or of small caliber, a urethral obstruction should be suspected. Meatal stenosis is usually evident with inspection of the caliber of the urethral meatus. The vulva should be examined for urine seepage. In girls with ectopic ureter, a constant moistness is observed in the introitus. Regularly drying the introitus with toilet tissue will show a persistent leak of urine.

\section{Investigations}

Urinalysis is the most important screening test in a child with daytime wetting. Children with UTI usually have white blood cells or bacteria evident in the microscopic urinalysis. Children with neurogenic bladder, urge syndrome, urethral obstruction, and ectopic ureter have a predisposition to UTI. If the history or the urinalysis suggests UTI, urine should be sent for culture and sensitivity. Urethral obstruction might be associated with red blood cells in the microscopic urinalysis. A random or first-morning specific gravity greater than 1.020 rules out diabetes insipidus as the cause of the wetting. Patients with diabetes mellitus have glucose in the urine.

Ultrasound of the urinary tract is an excellent noninvasive screening study and should be considered in patients with persistent daytime wetting. Patients with urethral obstruction or neurogenic bladder have a thick, trabeculated bladder wall or elevated post-void volume of residual urine. ${ }^{21}$ Residual urine volume is normally $<10$ $\mathrm{mL}$. There are several formulas to estimate bladder volume by ultra- 
sound. Hiraoka et $a^{31}$ reported accurate estimation of bladder volume with the formula: volume $(\mathrm{mL})=$ depth $(\mathrm{cm}) \times$ height $(\mathrm{cm})$ $\times$ width $(\mathrm{cm}) \times 0.68+4(\mathrm{~V}=\mathrm{DHW}$ $\times 0.68+4)$. Erasmie and Lidefelt ${ }^{32}$ reported accurate results with the formula: volume $(\mathrm{mL})=$ longitudinal diameter $(\mathrm{cm}) \times$ transversal diameter $(\mathrm{cm}) \times$ sagittal diameter $(\mathrm{cm}) \times 0.52 .^{32}$

If a urethral obstruction is suspected based on the presence of an abnormal urinary stream or an abnormal ultrasound, a voiding cystourethrogram (VCUG) should be performed.

If a neurogenic bladder is suspected, a VCUG should be performed. The classic radiologic feature of a neurogenic bladder is a trabeculated bladder with a "Christmas tree" or "pine cone" configuration.

Uroflowmetry is a simple noninvasive measurement of urine flow rate that might help identify patients with neurogenic bladder, urge syndrome, or urethral obstruction. ${ }^{21}$

Urodynamic studies obtained during a cystometrogram or a video-cystometrogram help to clarify the diagnosis of neurogenic bladder or urge syndrome. ${ }^{25,33}$

\section{Management}

One of the most important reasons to treat daytime wetting is to help minimize embarrassment of school-age children and parents' frustration. In a study of 2,000 schoolchildren living on four continents, "wetting pants in class" was the third most stressful event possible for school-age children, ranking only behind "losing a parent" and "going blind." ${ }^{16}$ It is important to involve the schoolteacher in the management of children with daytime wetting. A sympathetic teacher will encourage the child to go to the bathroom at recess or between classes and will help to avoid the embarrassment of episodes of incontinence. Children should have a change of clothes at school and a plastic bag in which to store the wet clothes.

Children who hold the urine to the last minute should be counseled to respond promptly to the need to void. Parents should remind children to void before leaving the house for any reason. When parents observe a child fidgeting or adopting a posture otherwise suggestive of the need to void, they should ask the child to void. Although the child might deny the need to void, we find it helpful to advise these children that going to the bathroom regularly is a "rule," much as brushing the teeth or putting on clothes are rules. The child should be further advised that it does not matter whether any urine comes out, it is still important to try to void. There is almost always some urine forthcoming in this situation. It is important to be supportive and reassuring to children who wet because they hold the urine to the last minute. There is no role for punishment in this situation. These children are not wetting to create a problem; they are wetting because they are absorbed in healthy play activities which, to them, are more important than going to the bathroom. With appropriate instruction, patience, and positive reinforcement, the problem will resolve over time. Preschool children who defer micturition might respond to a reward system of praise or a star or sticker chart. Parents with children who fear toilets outside the home might mitigate these fears by teaching their children how to clean the toilet seats in public bathrooms.

Antibiotics are necessary if UTI is the cause of the daytime wet- ting. ${ }^{34}$ If UTI is the only cause, the wetting should resolve with an appropriate antibiotic. If the child continues to have symptoms of daytime wetting or other symptoms of voiding dysfunction notwithstanding successful treatment of the UTI, an underlying anatomic problem should be suspected and appropriate diagnostic imaging studies are indicated. For children with episodes of UTI that recur as frequently as every 1-2 months, it may be helpful to prescribe a $2-3$ month course of antibiotic prophylaxis.

For children with constipation, treatment with a high-fiber diet, mineral oil, laxative, or enema program will help evacuate the bowel and normalize bowel movements.

Girls with vaginal reflux of urine should be instructed to spread the labia with each void. Sitting with knees wide apart or sitting backward on the toilet seat also facilitates opening the labia.

Children with the postvoid dribble syndrome should remain in the bathroom until the sensation has passed. During this time, the child can either read or attend to other aspects of personal hygiene. Some children wipe so frequently and so hard that the introital area is traumatized. Parents should teach the child to gently pat the area dry with soft tissue paper.

Parents of children with the daytime frequency syndrome should be reassuring and supportive. Activities should be planned with access to a bathroom in mind. Anticholinergic medications are not successful in these children. However, indomethacin has been reported to improve the symptoms. ${ }^{35}$

When giggle incontinence, stress incontinence, or emotional stress is the cause of the wetting, the patient should be advised to 
avoid the specific circumstance that will trigger the incontinence. When a situation likely to lead to incontinence is anticipated but cannot be avoided, it may be helpful for the patient not to drink excessive amounts of fluid in order to reduce the amount of urine in the bladder, to void prior to the activity, and to wear an absorbent pad in the underwear.

Brocklebank and Meadow ${ }^{13}$ reported successful treatment of giggle incontinence with a sympathetic approach, confidence-building measures, advice about posture, and the anticholinergic medication propantheline. Patients should be advised to assume a sitting position with laughter: this posture exerts pressure on the perineum, closes the urethra, and may prevent urinary incontinence. ${ }^{13}$

In children with neurogenic bladder, the underlying cause should be treated whenever possible. Surgical treatment is available for spinal cord tumors and tethered cord. If the cause cannot be treated, or if residual neurogenic damage is present after surgical treatment, management of these children should include regular voiding every 1.5 to 2 hours, manual expression of the bladder, clean intermittent self-catheterization, or anticholinergic medications. ${ }^{17,36}$ Urinary diversion, bladder augmentation, or an artificial urinary sphincter may be appropriate in selected cases. ${ }^{17}$

If urethral obstruction is identified, the child should be referred to a pediatric urologist for surgical repair of the obstruction.

Physiotherapy may be helpful in some patients with daytime wetting due to giggle incontinence, stress incontinence, neurogenic bladder, or urge syndrome. ${ }^{37-39}$ Voluntary contraction of the pelvic floor muscles is accompanied by a relaxation of the detrusor muscle. Hendrickx-DeBelva and Proesmans $^{37}$ reported that exercises to strengthen the abdominal wall and pelvic floor muscles, and improved posture for micturition improved or cured incontinence in $75(75 \%)$ of 100 patients with dysfunctional voiding. Schneider et $\mathrm{al}^{38}$ reported that Kegel exercises are an effective means of inhibiting involuntary detrusor contractions in children with urge incontinence. Kegel exercises consist of tightening the pelvic muscles and holding the contraction for 5 to 10 seconds, followed by a 5 -second rest period. Children should be instructed to perform 10 Kegel exercises three times a day at times other than when voiding. With this treatment, $47(60 \%)$ of 79 patients were cured of incontinence after an average of 2 months' treatment. ${ }^{38}$ Hellström et $\mathrm{al}^{39}$ reported normalization of symptoms over 3 years in $53(75 \%)$ of 70 patients with dysfunctional voiding using physiotherapy and biofeedback training. Normalization was defined as continence without urgency, a voiding frequency of three to six times per day, complete bladder emptying at a normal flow rate, and absence of residual urine (less than $10 \mathrm{~mL}$ ).

Halliday et $\mathrm{al}^{40}$ reported successful treatment of daytime wetting in $29(66 \%)$ of 44 children using an alarm device. The success rate was as good with a noncontingent alarm schedule as with an alarm that was contingent on an incontinent episode. Success was defined as 6 consecutive weeks without daytime wetting. A mean of 18 weeks was required to achieve success.

Anticholinergic medications may be helpful in patients with neurogenic bladder or urge syndrome. ${ }^{17}$ These medications reduce detrusor hyperactivity, increase the threshold volume at which uninhibited contractions occur, and enlarge the functional capacity of the bladder. Oxybutynin is commonly prescribed at a dosage of $5 \mathrm{mg}$ two or three times per day.

An ectopic ureter requires surgical repair.

Diabetes mellitus requires insulin therapy. Central diabetes insipidus requires treatment with 1-desamino-8-D-arginine vasopres$\sin$ (DDAVP). Nephrogenic diabetes insipidus may respond to treatment with hydrochlorothiazide.

\section{Prognosis}

The prognosis for dryness is excellent for children with daytime wetting due to most causes except neurogenic bladder and some causes of urethral obstruction. Malone et $\mathrm{al}^{19}$ reported on the long-term results of the treatment of incontinence in 109 patients with myelomeningocele. Only 31 $(38 \%)$ patients were reliably dry with a variety of treatments, including normal voiding, manual expression of the bladder, clean intermittent self-catheterization, indwelling catheter, anticholinergic medications, or some form of urinary diversion. Daytime wetting may persist following removal of the obstruction in some children with posterior urethral valves.

\section{Conclusion}

Daytime wetting is a common problem in childhood. Most patients with daytime wetting have an intermittent or self-limited problem with a benign and easily identifiable cause. A careful history is the most important aspect of the assessment of a patient with daytime wetting. A urinalysis is important to look for UTI. An ultrasound of the urinary tract that specifically assesses the blad- 
der is an excellent noninvasive screening study in selected patients. More invasive diagnostic imaging studies are necessary if the patient has symptoms or signs suggestive of neurogenic bladder, urethral obstruction, or ectopic ureter. With time and appropriate treatment, the prognosis is good for the majority of patients.

\section{Acknowledgments}

The authors thank Greenville Hospital System Health Sciences Library staff and medical editor Leslie Clugston, B.A., for help in the preparation of this manuscript.

\section{REFERENCES}

1. Blomfield JM, Douglas JWB. Bedwetting prevalence among children aged 4 to 7 years. Lancet. 1956;1:850-852.

2. Oppel WC, Harper PA, Rider RV. The age of attaining bladder control. Pediatrics. 1968;42:614-626.

3. Bloom DA, Seeley WW, Ritchey ML, McGuire EJ. Toilet habits and continence in children: an opportunity sampling in search of normal parameters. $J$ Urol. 1993;149:1087-1090.

4. Hellström AL, Hanson E, Hansson S, et al. Micturition habits and incontinence in 7-year-old Swedish school entrants. Eur J Pediatr. 1990;149:434-437.

5. Schmitt BD. Daytime wetting (diurnal enuresis). Pediatr Clin North Am. 1982;29:9-16.

6. Leung AKC, Robson WLM. UTI in infancy and childhood. Adv Pediatr. 1991;38: 257-285.

7. O'Regan S, Yazbeck S, Schick E. Constipation, bladder instability, urinary tract infection syndrome. Clin Nephrol. 1985; 23:152-154.

8. Homsy YL. Dysfunctional voiding syndromes and vesicoureteral reflux. Pediatr Nephrol. 1994;8:116-121.

9. Butcher $\mathrm{C}$, Donnai D. Vaginal reflux and enuresis. BrJ Radiol. 1972;45:501-502.

10. Robson WLM, Leung AKC. Post-mic- turition dribble syndrome. Hong Kong J Pediatr. 1993;10:49-52.

11. Robson WLM, Leung AKC. Extraordinary urinary frequency syndrome. Urology. 1993;42:321-323.

12. Zoubek J, Bloom DA, Sedman AB. Extraordinary urinary frequency. Pediatrics. 1990;85:1112-1114. Letter.

13. Brocklebank JT, Meadow SR. Cure of giggle micturition. Arch Dis Child. 1981;56:232-234.

14. Glahn BE. Giggle incontinence (enuresis risoria). A study and an aetiological hypothesis. BrJ Urol. 1979;51:363-366.

15. Cooper CE. Giggle micturition. In: Kolvin I, Mackeith RC, Meadow SR, eds. Bladder Control and Enuresis. London: Heinemann; 1973:61-65.

16. Meadow SR. Day wetting. Pediatr Nephrol. 1990;4:178-184.

17. Fernandes E, Reinburg $Y$, Vernier R, et al. Neurogenic bladder dysfunction in children: review of pathophysiology and current management. I Pediatr. 1994;124:1-7.

18. Reid CJD, Brzyskowski M. Lower urinary tract dysfunction in cerebral palsy. Arch Dis Child. 1993;68:739-742.

19. Malone PS, Wheeler RA, Williams JE. Continence in patients with spina bifida: long term results. Arch Dis Child. 1994;70:107-110.

20. Boemers TM, van Gool JD, de Jong TPVM, et al. Urodyndamic evaluation of children with the caudal regression syndrome (caudal dysplasia sequence). JUrol. 1994;151:1038-1040.

21. Fernandes E, Vernier R, Gonzalez R. The unstable bladder in children. $J$ Pediatr. 1991;118:831-837.

22. van Gool JD, de Jonge GA. Urge syndrome and urge incontinence. Arch Dis Child. 1989;64:1629-1634.

23. de Jonge GA. The urge syndrome. In: Kolvin I, MacKeith RC, Meadow SR, eds. Bladder Control and Enuresis. London: Heinemann; 1973:66-71.

24. Koff SA. Bladder-sphincter dysfunction in childhood. Urology. 1982;19:457-461.

25. Borzyskowski M, Mundy AR. Videourodynamic assessment of diurnal urinary incontinence. Arch Dis Child. 1987;62: 128-131.

26. Vincent SA. Postural control of urinary incontinence: the curtsy sign. Lancet.
1966;11:631-632.

27. Hinman F. Non-neurogenic neurogenic bladder (the Hinman syndrome) -15 years later. J Urol. 1986;136:769-777.

28. Phillips E, Uehling DT. Hinman ș̣ndrome: a vicious cycle. Pediatr Urol. 1993;42:317-320.

29. Barkai L, Szabó L. Urinary bladder disfunction in diabetic children with and without subclinical cardiovascular auto. nomic neuropathy. Eur $J$ Pediatr. 1993;152:190-193.

30. Robson WLM, Leung AKC, Elliott $F$, et al. Penile compression - a sign of urethral obstruction. Child Nephrol Urol 1992; 12:30-31.

31. Hiraoka M, Tsukahara H, Tsuchida S, et al. Ultrasonographic evaluation of bladder volume in children. Pediatr Nephrol. 1993;7:533-535.

32. Erasmie U, Lidefelt KJ. Accuracy of ultrasonic assessment of residual urine in children. Pedialr Radiol. 1989;19:388-390.

33. Dinneen MD, Duffy PG. The value of urodynamic studies. Arch Dis Child. 1993;67:177-179.

34. Williams MA, Noe HN, Smith RA. The importance of urinary tract infection in the evaluation of the incontinent child. J Urol. 1994;151:188-190.

35. Luo X. Indomethacin treatment in children with daytime frequency of micturition. Pediatr Nephrol. 1992;6: 445-447.

36. I.indehall B, Möller A, Hjälmås K, et al. Long-term intermittent catheterization: the experience of teenagers and young adults with myelomeningocele.J Urol. 1994;152:187-189.

37. Hendrickx-De Belva A, Proesmans W. Ask the Expert. Pediatr Nephrol. 1993;1:14.

38. Schneider MS, King LR, Surwit RS. Kegel exercises and childhood incontnence: a new role for an old treatment. J Pediatr. 1994;124:91-92.

39. Hellström AL, Hjälmås $\mathrm{K}$, Jodal U. Rehabilitation of the dysfunctional bladder in children: method and 3-year follow-up. J Urol. 1987;138:847-849.

40. Halliday S, Meadow SR, Berg I. Successful management of daytime enuresis $u s-$ ing alarm procedures: a randomly controlled trial. Arch Dis Child. 1987; 62:32-137. 